\title{
AN EXPLORATIVE STUDY TOWARDS USING VR SKETCHING AS A TOOL FOR IDEATION AND PROTOTYPING IN PRODUCT DESIGN
}

\author{
J. Joundi ${ }^{凶}$, Y. Christiaens, J. Saldien, P. Conradie and L. De Marez \\ Ghent University, Belgium \\ $\bowtie$ jamil.joundi@ugent.be
}

\section{Abstract}

The advancements in the field of VR allow designers to use VR as a technology for sketching ideas in a virtual space. In this paper, Gravity Sketch (a VR sketching software) is used as an ideation sketching tool in the process of product styling. The goal of this research is to examine the advantages and points-of-pain when using virtual reality tools in the process of product styling. 29 Master students used the VR sketching tool in their design process and all of them had feedback and insights on the tool.

Keywords: virtual reality (VR), sketching, design tools, computer-aided design (CAD), humancomputer interface

\section{Introduction}

In the profession of industrial design there are many digital tools available to support the design process of new products. These digital tools are used for different goals. In most cases they visualize the look of a product. After a process of sketching, a 3D model is made to check whether it matches the shape the design team envisioned. Currently, a 3D model is created first in CAD software and later a 2D render is created to contextualize the 3D model and use it in marketing and user feedback. In this paper we evaluate sketch based 3D VR modeling as a tool, used in an industrial design education setting. Through this educational setting the assignment was given to design and style a new drone device.

This paper questions the flow in which products could be developed. The designer has a wide array of tools to his disposition that are not immersive. By allowing users to create virtual models in immersive $3 \mathrm{D}$ virtual environments, it is possible for the designer to better adapt the design to the context than when the design is placed in the suited context afterwards. We are interested in the benefits and drawbacks when designing objects in VR.

\subsection{Process, protocol and tools for ideation}

Designers use many ways to generate ideas in the process of designing a new product or system. Sketches are mostly used to communicate and draft design ideas to other people involved in the process of designing new products. In the beginning of the process designers gather as much relevant information as possible about (the context of) the product. The start of the design project is often initiated by a design brief which formulates the question from the party demanding a new product or system. Mood boards are frequently used for mapping out solutions that are similar to the envisioned design. "Designers need qualitative and imprecise external visualizations to interact with their mental 
images. And they need to be in continuous interaction with them to make design decisions". Many different types of representations: mood boards, sketches, morphological maps, scale models and prototypes serve as tools to help define the form of a product. Where CAD tools often are used to represent already designed ideas (Dorta et al., 2008).

In Warell's (2004) research four steps are proposed for the evaluation of form syntactics in the design process:

1. selection of design elements to be studied

2. generation and implementation of syntactic variations of selected design elements

3. assessment of visual effect achieved by each variation

4. evaluation and conclusion regarding syntactic functionality

While the assignment was mainly on designing a drone, it is also important to design for different characteristics (like durability/price/usability/...)."Product design is a skill and the aforementioned trade-offs can only be made through design experience. Moreover, products that are optimized towards one characteristic, for example cost efficiency, often are shallow in other aspects like durability, experience offered, or aesthetics." (Frens and Form, n.d.)

During a normal styling process, the designers start off with sketching many ideas on paper. When a sketch is promising, a clearer sketch is drawn and a 3D physical model is created of the sketch. A lot of the designer's effort is aimed at creating a design that meets the needs of the target group and matches the design language and product DNA of the overall product portfolio. Another aspect that should be regarded in the design process is that the design allows for the expected functionality of the product affordances (e.g. placement of the buttons on a drone, protection for the blades, etc.). This is an iterative process and while there is no hard science on this topic there is a logical sequence order to which all the above mentioned aspects should be incorporated in the design.

Most designers follow the design thinking cycle consisting of six consecutive steps: Empathise, Define, Ideate, Prototype and Test (Liu et al., 2011). Iterations on this process can be done according to the desired end result (see Figure 1).

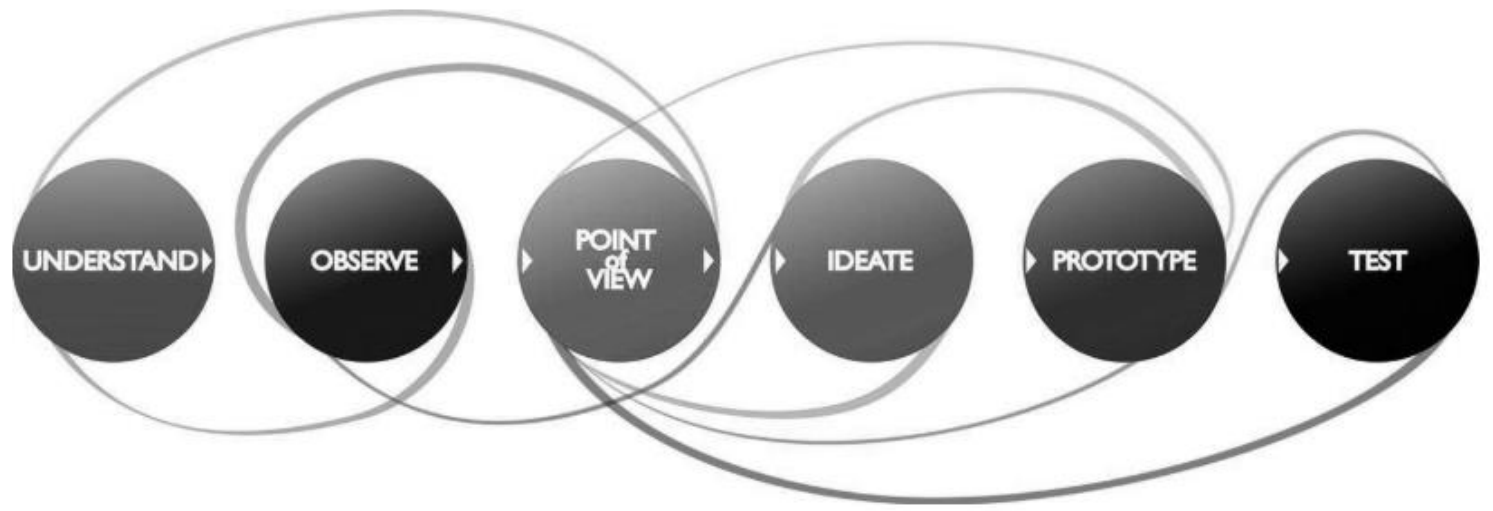

Figure 1. Design thinking flowchart (Liu et al., 2011)

Another method of ideation is mentioned in the research of Abidin et al. (2011). Morphing is used as a tool to change from one shape to another in a sequence of slightly different sketches.

The author states in the findings of his research that shape aspects can better be assessed according to the freedom in the representation. This means that a shape aspect assessment is done better in a 3D view as opposed to a $2 \mathrm{D}$ (frontal) view.

\subsection{Computer aided industrial design software in VR}

In this course students act according to a workflow that is applied often in the automotive industry (seen in Figure 2). That industry is very structured by nature while undertaking considerable efforts to digitalize the process (Bae and Kijima, 2003). Therefore the structure of the CAID course is based upon that of the automotive styling process. They divide the process of computer aided styling (CAS) in three parts. The VR sketching tool used in our study is situated in embodiment design similar to 3D direct shape modeling (see Figure 2). Further important research involving shape design in automotive is that of Tovey, Porter and 
Newman (Tovey et al., 2003). They conclude that in automotive design, designers start often from drawing shape lines that are critical for determining the final look of car. In line with this research we wanted to find out if the students use VR: (1) for creating these shape lines, (2) how they respond to this new tool as first time users and (3) what the perceived value is when using VR.

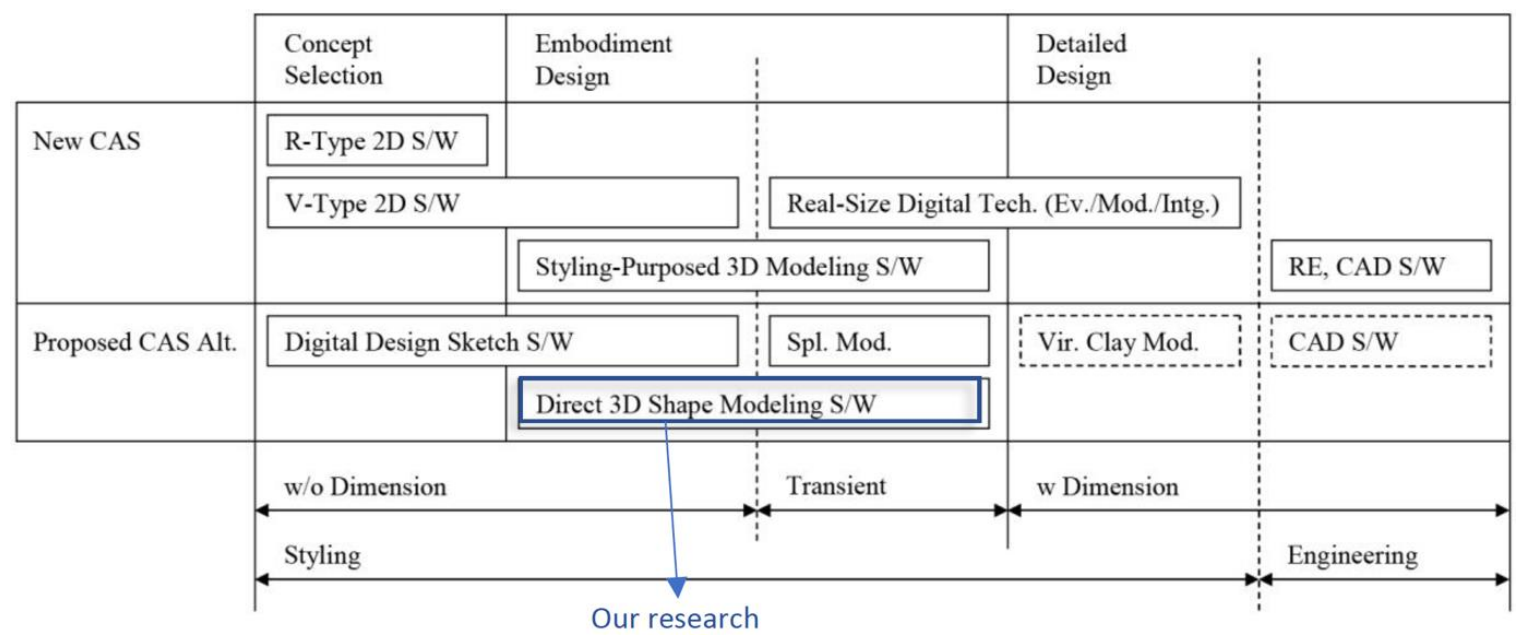

Figure 2. Automotive styling process (Bae and Kijima, 2003)

Bae and Kijima (2003) have pointed out that several industry players experiment with VR tools to either digitalize the styling process or to evaluate 2D/3D shapes. At the time of their research, VR technology was still in a premature state.

In this specific case study, scale is less of an issue when comparing to automotive industry. Our main interest goes to (1) generating many ideas in a short period of time (2) facilitating the transition from a 2D sketch, on paper, to a 3D representation of the concept idea.

Previously students started building a physical mock up immediately after their concept was approved. Observation taught us that this process was very labour intensive and the lack of spatial insight on how to translate a 2D sketch to a 3D mock was a major cause of delay. Some solved this using the Subdivision Modeling technique in Siemens NX.

\section{Related work}

Virtual reality sketching tools have been around for a long time in academic research (Barrera Machuca et al., 2017; Zeleznik et al., 2007). However, studies on the usability of recent VR prototyping tools is lacking. Building further on the work of Philip Ekströmer (Wever, 2018) we did a usability study on using virtual reality sketching for design ideation (using 'Gravity Sketch'). Gravity Sketch is a consumer ready software that allows designers to sketch objects in 3D in real-time. Another study that resembles our work was done by Vincent Rieuf (Rieuf and Bouchard, 2017). VR was used as a tool for inspiration, CAD and shape study. The main difference is that they took a general approach to compare VR to sketching where we focus more on one application (Gravity Sketch) and evaluated its use for designers. Additionally, usability studies on older 3D sketching systems have already been done (Cook and Agah, 2009). VR is also used in industry by large companies that use different set-ups, varying from life-size screens to HMDs (Berg and Vance, 2017). This is done for visual testing mainly and presentations for managers and management. The ILoveSketch system (Bae et al., 2008) works similar to the setup we tested, except without an HMD. The research shows that a lot of drawing skills are required to be good at 3D sketching on a tablet. These VR interfaces can also be used for other applications. Research by Yong Wang (Baraff and Witkin, 2013) shows that Virtual Reality could also be used for testing in virtual assemblies. A lot of development is already done in this area, though it would be interesting to test 3D models that are created in VR. Virtual models of factories can be used to test ideas of workflow and design on the factory floor as proposed by Choi et al. (2015).

Learnings from the research of Beattie et al. (2015) include that if a controller input is done with motion capture of the hands, the tools become very accessible. In the research of Arora et al. (2017), it was found that the lack of surfaces produces the inaccuracy of the drawn model. In their findings it 
also seems like drawing in the horizontal plane is the easiest for the participants. Other research from Arora et al. (2018) also focuses on the fact that generally speaking people draw better on a 2D surface than in 3D directly. In the commercial market, Gravity Sketch (the 3D VR sketching software used) has a Wacom drawing tablet integration for their software and a function to be able to draw in one fixed plane (planar functionality). In the research of Jackson and Keefe (2016) a technique where 2D sketches are traced over in VR is used to create 3D models. Levent, Burak, Kara and Kenji Shimada (Kara and Shimada, 2007) tell how 3D sketching can be used for product design.

\section{VR sketching experiment}

\subsection{Experiment setup}

Currently there are several options for drawing in VR; e.g. Tiltbrush, Gravity Sketch VR, Quill. Even though sketching in VR is not a new technique, newer sketching tools have the benefit of a more rapid idea development trajectory. In line with the research of Wever (2018) we check which factors influence the use of VR in product design (Vince, 1999). We conducted an observational study with 27 master students in design. The objective of the study was to see whether VR design tools (in this case Gravity Sketch) can be used for ideation design (of a drone) and how the learning experience evolves after several trials using virtual prototyping tools. The learning curve of using VR prototyping tools in a design process for these students was assessed. Qualitative testing was completed before and after using the VR prototyping tools. Students had to test the VR interface both with and without context. This was used to test whether adding extra context (background images, inspirational images, $3 \mathrm{D}$ reference models) were useful when designing in VR.

\subsection{Method}

The participants of this observational study were 17 male, 10 female with their age varying from 21 to 25. These master students are already familiar with CAD modelling software but none of them had ever used the proposed VR sketching software.

The in-situ observations were done closely with 18 students by one researcher. The other nine students were observed by a second researcher without one to one interaction. After the experiment the students filled in a questionnaire to give supporting feedback for the observations.

The observations were performed over a time period of several weeks due to the fact that the students are not available at all times and because one setup was used so that one student at a time could be observed.The room ( $4 \mathrm{~m}$ by $3 \mathrm{~m}$ ) for the observations was inside a school for higher education in design and is located in Flanders (Belgium). The base station of the VR system were mounted on the ceiling. With two students tracking issues occurred.

The goal of the observational study was to assess the impact of using VR tools in the styling process of products (in this use case a drone). The students were asked to design a drone in the Masters course of styling. This drone has two requirements, it should be designed for its functionality which could be chosen by the students themselves (for example: emergency drone, sports drone, etc.). The other requirement was that an animal transfer was done to their design. This means that the drone should have features or shapes in it that are inspired by nature. The students were given the opportunity during the course to make use of the VR system to test shapes, ideate and iterate on their drone model. The use of contextual information plays an important role in the proposed design assignment. If the experience is more immersive, then the feedback of participants will also be richer. The students were divided in two groups: group one (15 students) that could design their drone with contextual objects (reference images, 3D models, background images, reference sketches). Group two (12 students) had to design in VR without contextual objects. Another goal was to investigate how significant the effect of context in VR is in the design process. Many students wanted to use VR in the beginning of their design process.

\subsection{User observation}

In our user test we performed an observational study where students were asked to design and style a drone for a Masters course (Design, styling \& CAID). This observational study consisted out of: 
1. online survey before sketching in VR

2. user observations during sketching in VR

3. interviews after sketching in VR

4. online survey after sketching in VR to reflect on their experience

\section{Results}

The results of the observations were very diverse. Some students reported dizziness in VR, others found that it was not precise enough, others found it very liberating to test ideas in $3 \mathrm{D}$ in real time.

\subsection{VR usability}

Of the 27 students, nine replied that the experience was good, five replied the experience was great to amazing, six students found the experience interesting, one student said the experience was normal and six mentioned issues (see Figure 3). The envisioned use of Gravity Sketch according to the students can be seen in Figure 4. When asked about the limitations of Gravity Sketch a lot of feedback revolved around the precision of the tools and functionalities that were missing compared to CAD tools (see Figure 5).

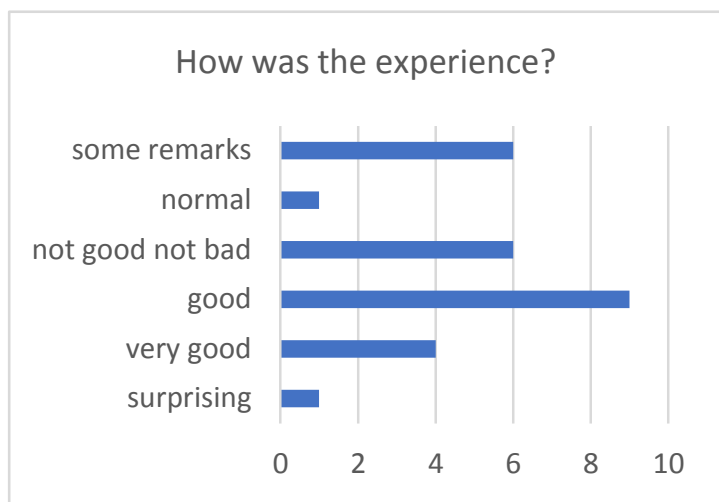

Figure 3. "How was the experience?"

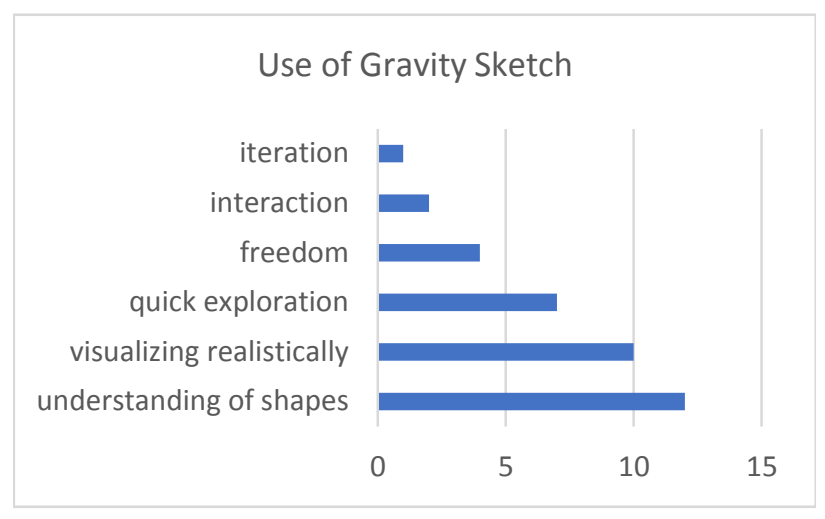

Figure 4. "What is the use of Gravity Sketch?"

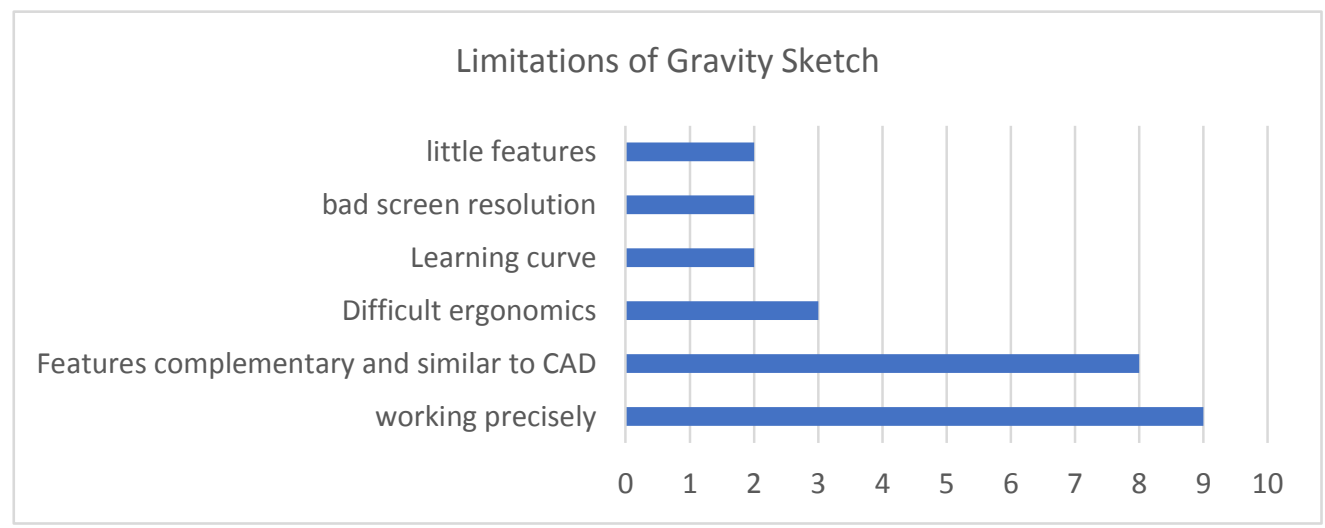

Figure 5. What are the limitations of Gravity Sketch?

\subsection{Envisioned application}

On the question "How do you think Gravity Sketch can influence the design process?" many students answered in the direction of visualising products (see Figure 6). On the question "how would you like to use Gravity Sketch as a designer?" many replied with the remark to visualise 3D cad models (render, compare models, 2D sketches in 3D, ...) (see Figure 7). 


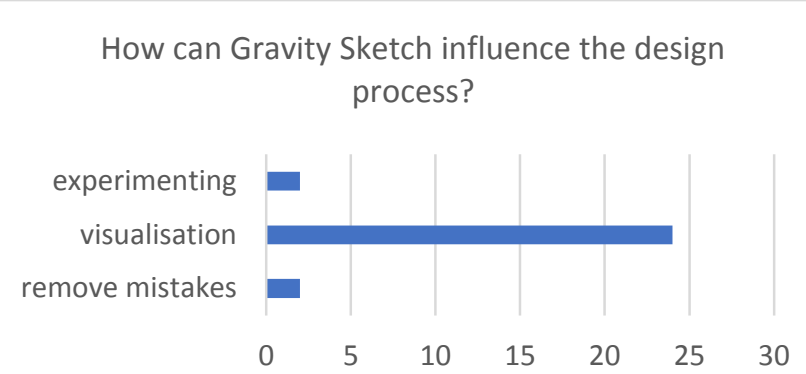

Figure 6. "How can Gravity Sketch influence the design process?"

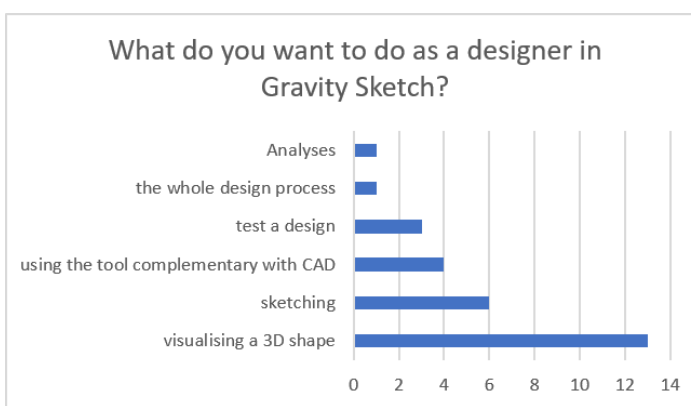

Figure 7. "What do you want to do as a designer in Gravity Sketch?"

\subsection{Importance of context}

Research focus was placed on establishing whether context helps designers in VR to find more inspiration and be more immersed while designing. Questions about immersion were asked to both groups. Secondly, the majority of participants were assisted and observed while designing with and without context. Most students (from group one) would use the reference images they bring inside the VR application as a scale reference and a basis to sketch onto (15 replies) (see Figure 8). Other students would use the reference images more for tracing lines and to work more precisely (which was the case with the ones that used reference images). Group two was not able to use contextual material. Their answers were quite similar to the group with contextual tools, except that no one in this group would see the point of testing out designs in VR (probably because the application did not support this function) (see Figure $9 \& 10$ ).

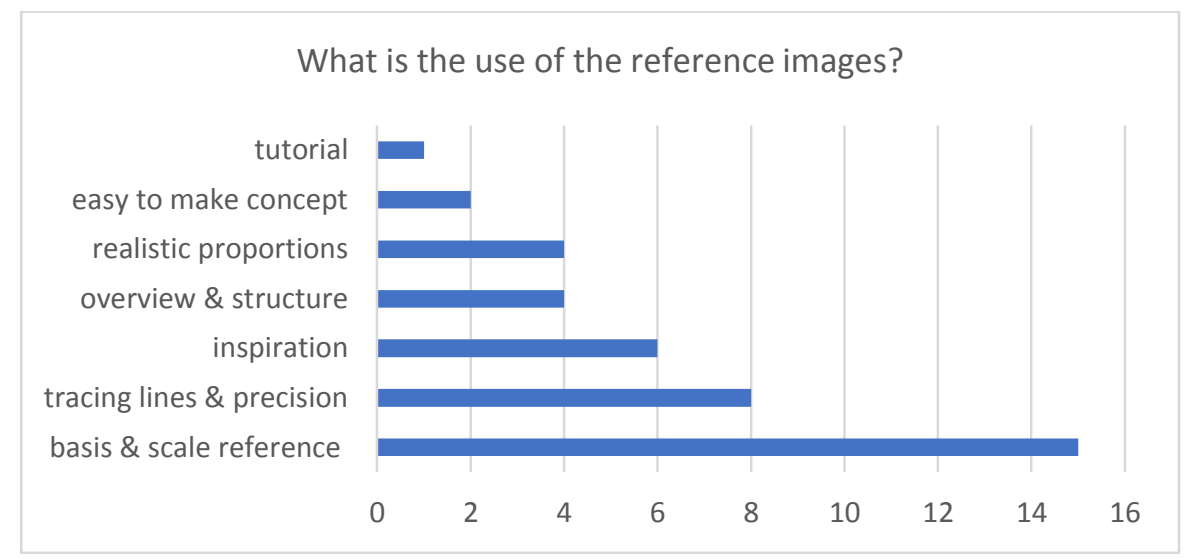

Figure 8. "What is the use of reference images?"

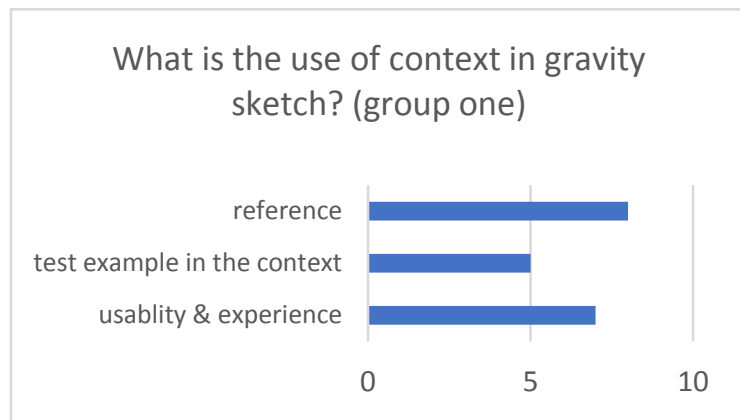

Figure 9. "What is the use of adding context in VR?" (group one)

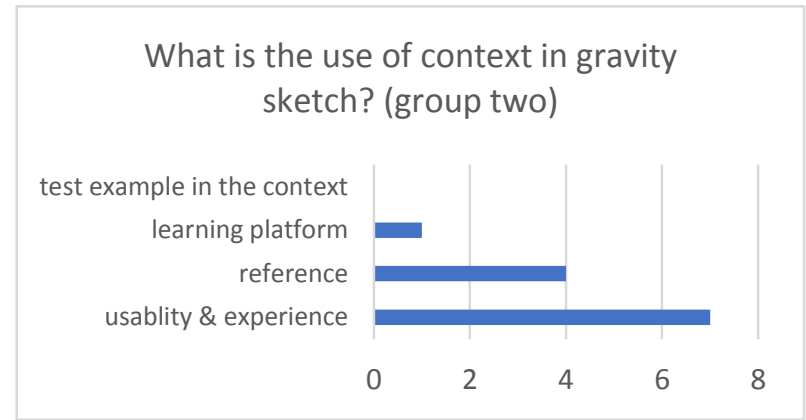

Figure 10. hat is the use of adding context in VR" (group two) 


\subsection{Observations}

Think aloud protocol was used while the students were designing their drones in VR.

Thirteen different problems were observed (Table 1) and mapped on the four steps according to Warell (2004) found in research (see section 1.1).

Table 1. Different observed problems with according category and phases

\begin{tabular}{|c|c|c|}
\hline $\mathrm{N}^{\circ}$ & & Steps \\
\hline & Creativity & \\
\hline 1 & $\begin{array}{l}\text { Designers who didn't know what drone they wanted to make had difficulties with starting } \\
\text { the design in VR. Mostly because there were multiple things that were difficult: the way of } \\
\text { sketching, the controls and placement of functions, the thought process of trying out } \\
\text { different concepts, etc. . }\end{array}$ & 1 \\
\hline 2 & $\begin{array}{l}\text { VR was not a great tool for idea generation: students using VR without a clear idea of what } \\
\text { shape they want to produce experienced a lot of difficulty due to the pressure to come up } \\
\text { with ideas in the short time frame. }\end{array}$ & 1 \\
\hline \multirow[t]{2}{*}{3} & $\begin{array}{l}\text { When reference images are used (in this case of animals), students seemed to copy (track } \\
\text { and trace) the shapes directly from pictures they loaded in. This resulted in literal } \\
\text { translations of animal design. }\end{array}$ & 2 \\
\hline & Technical & \\
\hline 4 & $\begin{array}{l}\text { Designers that did know what drone they wanted to make had difficulties designing this } \\
\text { drone (due to controls and lack of precision). }\end{array}$ & 1 \\
\hline 5 & $\begin{array}{l}\text { When asked what the tool should be used for a lot students replied for visualising their } \\
\text { product on true scale. If VR was more versatile, students would want to change designs in } \\
\text { VR that they have created earlier. }\end{array}$ & 2 \\
\hline 6 & $\begin{array}{l}\text { Students also used reference images of their own designs (sketches on paper, or even } \\
\text { screenshots out of CAD software). It would make more sense to be able to edit the CAD } \\
\text { model directly in gravity sketch and have a hybrid solution. The three students who used 3D } \\
\text { models as reference objects were able to work more precisely than the students who used } \\
\text { only drawings. }\end{array}$ & 3 \\
\hline 7 & $\begin{array}{l}\text { Even though the students had a very short time frame to draw their design in VR ( } 30 \\
\text { minutes per student) they succeeded at making a model that represent their idea. This is not } \\
\text { possible with first time users of advanced CAD tools. Which lets us conclude that VR } \\
\text { sketching produces end results faster. }\end{array}$ & 3 \\
\hline 8 & $\begin{array}{l}\text { Another observation was that students often complained that they were not able to work } \\
\text { very precisely, which often made them doubt the use of VR as a tool. }\end{array}$ & 3 \\
\hline \multirow[t]{2}{*}{9} & $\begin{array}{l}\text { Some students used a custom model to work on the casing of their drone. In these cases the } \\
\text { end result felt more realistic as supposed to students working without a reference. }\end{array}$ & $1,2,3,4$ \\
\hline & Physiological & \\
\hline 10 & $\begin{array}{l}\text { Drawing directly in } 3 \mathrm{D} \text { is difficult because this is totally new cognitively and } \\
\text { physiologically to draw in this fashion }\end{array}$ & $1,2,3,4$ \\
\hline \multirow[t]{2}{*}{11} & $\begin{array}{l}\text { Some students found the experience discomforting (probably because they feel lost in the } \\
\text { VR space or because of a physical reaction to } 6 \text { DOF) }\end{array}$ & $1,2,3,4$ \\
\hline & Process & \\
\hline 12 & $\begin{array}{l}\text { The VR sketching tool was used mostly in the ideation and prototype phase of the design } \\
\text { process. This indicates that the tool would be used primarily for exploration. }\end{array}$ & 2 \\
\hline 13 & $\begin{array}{l}\text { Some students wanted more sessions to optimise and finalise their design. Which indicates } \\
\text { that for some students VR was an interesting tool to use in their design process. }\end{array}$ & $2,3,4$ \\
\hline
\end{tabular}

\subsection{Visual quality of the sketches}

After analysing the sketches (Figure 11) with two university teachers in product design a few conclusions could be made from comparing the VR sketches with the final renders of the project.

The findings were that many VR sketches resembled the final render (Figure 12) of the drone they designed during the course. This resemblance occurred mostly in a direct translation of their idea in a 
3D shape similar to the final result (16 students). Other students made something different entirely (four students).

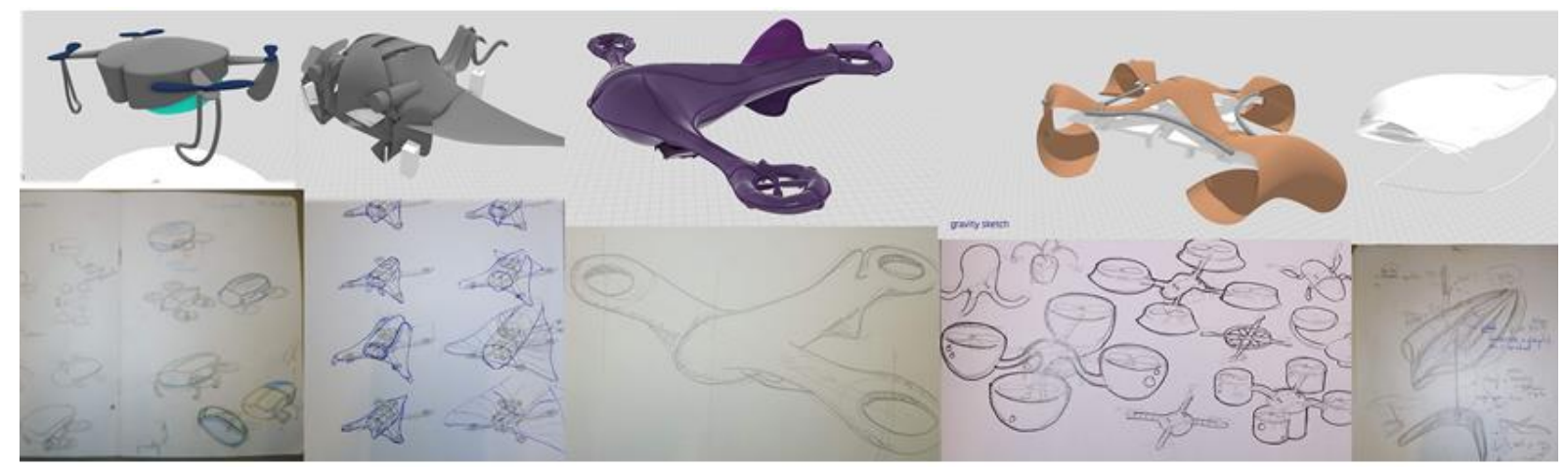

Figure 11. Comparison of pencil and paper sketches (bottom row) with VR sketches (top row)

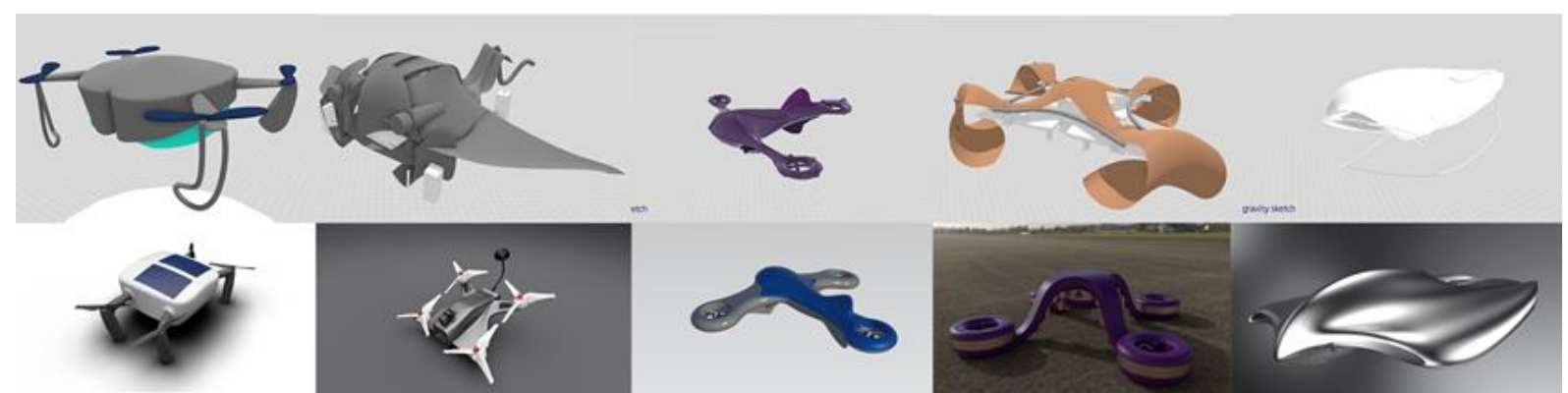

Figure 12. VR sketches created during the design process (top row) and the final render of the same product (bottom row)

Another group who based the final design on what they sketched in gravity sketch drew more in terms of rough shapes and were trying to find the right proportions and lines (seven students). It was observed that the students started off with a shape they were inspired by and translated it literally to their design (Table 1 $\mathrm{n}^{\circ} 3$ ). Afterwards these students were trying to make it less obvious how they copied the shape and worked on making the drone feel more like a drone (nine students of the 16 mentioned earlier).

Warell's four steps (Warell, 2004) were mapped on the observations of students drawing in VR.

The selection of design elements to be studied (step one) was mainly done outside of Gravity Sketch. The students who did not have a clear image in mind what kind of drone would be produced, struggled heavily in using VR in the beginning. (See problems $n^{\circ} 1,2,4,9,10$ and 11).

As for the generation and implementation of syntactic variations of selected design elements (step two), this was the aspect where most students used the software. Mainly because changing the design and assessing the design (step three) are instantaneous, students are motivated to optimise the rough shapes in their design and assess which shape works best. (See problems $n^{\circ} 3,5,9,10,11,12$ and 13). The third step for the evaluation of form syntactics in the design process is the assessment of visual effect achieved by each variation. Although most designs stayed in the headset with the designer, communication on shapes happened. The students who did their selection of elements outside the software would communicate and ask for tips how to achieve shapes rather than opinions whether one shape is better than another. The comparison of shapes was rather an assessment that happened by the designer himself. (See problems $n^{\circ} 6,7,8,9,10,11$ and 13). Due to detail design in VR can be difficult to do, the evaluation and conclusion regarding syntactic functionality (step four) was done outside the VR environment. This is still seen as a weakness in the process of using VR as a tool for styling because other applications are needed for this phase. Some examples are: CAD models, photo shopped images of screenshots or even detailed prototypes. (See problems $n^{\circ} 9,10,11$ and 13)

The students' feedback and the observations made it is possible to map where the VR sketching application could be used in the design process. The students used the software a lot to create rough shapes and to assess whether the shape fits the envisioned shape they sketched on paper. When the general shape is 
created and assessed, the students tend to create the shape in another way (through a combination of CAD, Photoshop and/or prototype) to do the final detail design and styling of the product.

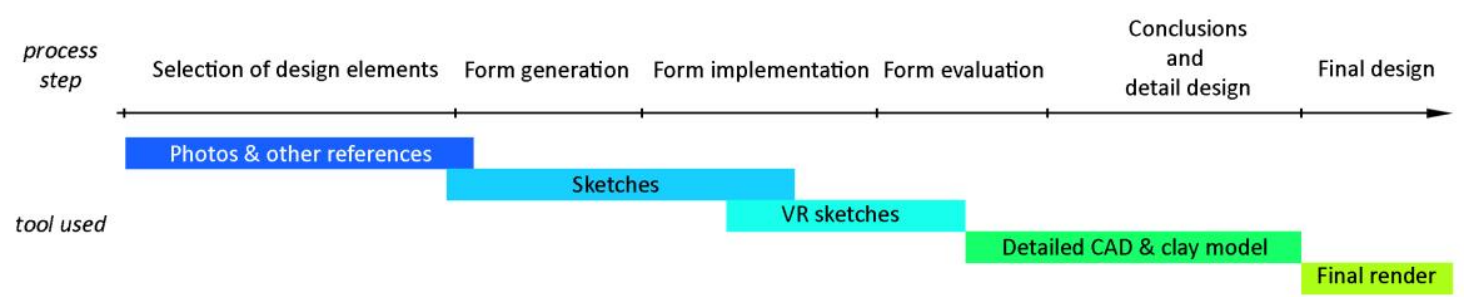

Figure 13. Design tools used by participants mapped on the design process according to Warell (2004)

\section{Conclusion \& future work}

In this research an observational study was performed where 3D VR sketching was used a tool in the design process of last year design students. We used surveys before and after the use of VR as a sketching tool in their design process. The survey focused on their perception on VR as a tool for designers.

The 3D drawings were also compared with the end results together with two design university professors. The final renders from the students resembled their "early VR sketches" quite well.

The following positive observations were made:

1. VR can be a helpful tool in mediating from a shape idea towards the construction of that idea into an enclosed shape.

2. The master students were able to create the desired shapes in a limited time frame (one session of 30 minutes).

3. The students saw a lot of potential in the tool for visualising their shape.

The following problems were observed:

1. Gravity Sketch was not used as a form finding tool because: drawing in 3D space with a few references is complex, the tool has a steep learning curve (especially handling the controllers) and there were only 2 VR stations present to work on so drawing time was limited.

2. Students who used reference material (3D models and sketches) were able to style their 3D model faster and easier than students designing with objects.

To progress in this research, the study could be repeated with the upcoming features and better VR hardware. The ways how the controls work seems to be a hurdle for the use of VR sketching tools. That is why there can be experiments with different controllers (oculus, vive or using leap motion sensors). Additionally, drawing tablet implementation is being developed which could be interesting if it is compared to the controllers in speed and end result. While spatial references make it a lot easier to design objects in VR, another study can be performed to research the specific impact of reference material and how the use of context can further enhance the design process.

Apart from being a very powerful tool for "full-fledged" designers the tool also seems very promising for design education as it allows students to draw three dimensional shapes instantly which seems to be useful for development of depth perception and mental rotation of objects.

\section{References}

Abidin, S.Z., Warell, A. and Liem, A. (2011), "The significance of form elements: A study of representational content of design sketches", Proceedings of the DESIRE'11 Conference on Creativity and Innovation in Design, pp. 21-30.

Arora, R. et al. (2018), "SymbiosisSketch", Proceedings of the 2018 CHI Conference on Human Factors in Computing Systems - CHI '18, No. April, pp. 1-15.

Arora, R. et al. (2017), "Experimental Evaluation of Sketching on Surfaces in VR", Proceedings of the 2017 CHI Conference on Human Factors in Computing Systems - CHI '17, pp. 5643-5654. 
Bae, S.-H. and Kijima, R. (2003), "Digital styling for designers: in prospective automotive design", Proceedings of Virtual Systems and Multi Media, No. 1, pp. 546-553.

Bae, S., Balakrishnan, R. and Singh, K. (2008), "ILoveSketch : As-Natural-As-Possible Sketching System for Creating 3D Curve Models".

Baraff, D. and Witkin, A. (2013), "Physically Based Modeling (2001)”, No. June, pp. 1-116.

Barrera Machuca, M.D. et al. (2017), "Multiplanes: Assisted Freehand VR Drawin", Adjunct Publication of the 30th Annual ACM Symposium on User Interface Software and Technology - UIST '17, pp. 1-3.

Beattie, N., Horan, B. and McKenzie, S. (2015), "Taking the LEAP with the Oculus HMD and CAD - Plucking at thin Air?", Procedia Technology, Elsevier B.V., Vol. 20 No. July, pp. 149-154.

Berg, L.P. and Vance, J.M. (2017), "Industry use of virtual reality in product design and manufacturing: a survey”, Virtual Reality, Springer London, Vol. 21 No. 1, available at: https://doi.org/10.1007/s10055-0160293-9.

Choi, S., Jung, K. and Noh, S.D. (2015), "Virtual reality applications in manufacturing industries: Past research, present findings, and future directions", Concurrent Engineering Research and Applications, Vol. 23 No. 1, pp. 40-63.

Cook, M.T. and Agah, A. (2009), “A survey of sketch-based 3-D modeling techniques", Interacting with Computers, Elsevier B.V., Vol. 21 No. 3, pp. 201-211.

Dorta, T., Pérez, E. and Lesage, A. (2008), "The ideation gap:. hybrid tools, design flow and practice", Design Studies, Vol. 29 No. 2, pp. 121-141.

Frens, J. and Form, I. (n.d.), Designing for Rich Interaction.

Jackson, B. and Keefe, D.F. (2016), "Lift-Off: Using Reference Imagery and Freehand Sketching to Create 3D Models in VR", IEEE Transactions on Visualization and Computer Graphics, IEEE, Vol. 22 No. 4, pp. 1442-1451.

Kara, L.B. and Shimada, K. (2007), “3D-Shape Creation for Industrial”, No. February, pp. 60-71.

Liu, J., Zhang, M. and Hu, X. (2011), "Understanding Design Thinking : a Process", Thinking, No. September, pp. 44-48.

Rieuf, V. and Bouchard, C. (2017), "Emotional activity in early immersive design: Sketches and moodboards in virtual reality", Design Studies, Vol. 48, pp. 43-75.

Tovey, M., Porter, S. and Newman, R. (2003), "Sketching, concept development and automotive design", Design Studies, Vol. 24 No. 2, pp. 135-153.

Vince, J. (1999), "Virtual Reality for Industrial Applications", In: Dai F. (Ed.), Displays, Springer-Verlag, Berlin, p. 173, ISBN 3-540-63348-0, available at: https://doi.org/10.1016/s0141-9382(99)00010-4.

Warell, A. (2004), "Towards a theory-based method for evaluation of visual form syntactics", Proceedings Fifth International Symposium on Tools and Methods of Competitive Engineering, pp. 913-922.

Wever, R. (2018), "Virtual reality sketching for design ideation", No. December.

Zeleznik, R.C., Herndon, K.P. and Hughes, J.F. (2007), "SKETCH: An Interface for Sketching 3D Screens”, $A C M$ SIGGRAPH 2007 Courses on - SIGGRAPH '07, available at: https://doi.org/10.1145/1281500.1281530. 